\title{
Performance measurement of electricity suppliers using PROMETHEE and balance scorecard
}

\author{
Mona Osati* and Manouchehr Omidvari
}

Industrial Engineering Group, Department of Industrial and Mechanical Engineering, Qazvin Branch, Islamic Azad University, Qazvin, Iran

\begin{tabular}{l}
\hline C H R O N I C L E \\
\hline Article history: \\
Received February 5, 2016 \\
Received in revised format April \\
15, 2016 \\
Accepted April 26, 2016 \\
Available online \\
April 27, 2016 \\
\hline Keywords: \\
Performance measurement \\
PROMETHEE \\
BSC \\
Energy
\end{tabular}
A B S T R A C T

\begin{abstract}
Performance measurement in energy industry plays an important role on increasing the productivity. Electricity is also among the most essential components of energy in mega cities like Tehran. The lack of a good service in this city may result unpleasant consequences on most civilians who live in this city. This paper presents an empirical investigation to measure the performance of six major electricity contractors in city of Tehran, Iran. The study implements grey numbers to handle any uncertainty associated with numbers. The study has also adopted four main perspectives used in balanced scorecard as part of PROMETHEE method to rank different contractors.
\end{abstract}

(C) 2016 Growing Science Ltd. All rights reserved.

\section{Introduction}

Performance measurement in energy industry plays an important role on increasing the productivity. Electricity is also among the most essential components of energy in mega cities like Tehran. The lack of a good service in this city may result unpleasant consequences on most civilians who live in this city. During the past few years, there have been tremendous efforts on using different methods for performance measurement. Tseng (2010) presented a method using different techniques for performance measurement. They used analytic network process (ANP) to analyze the dependence perspectives, the decision-making trial and evaluation laboratory (DEMATEL) was also applied to deal with the interactive criteria, and the fuzzy set theory was implemented to handle the uncertainty. Bentes et al. (2012) presented an analysis based on the integration of two methodologies, Balanced Scorecard (BSC) and AHP to generate a unified metric for the ranking of alternatives associated with performance measurement in telecommunication industry. Lee et al. (2008) presented a method based on the fuzzy analytic hierarchy process (FAHP) and BSC for assessing an IT department in the manufacturing industry in Taiwan. The results provided some guidance to IT departments in the manufacturing industry in Taiwan regarding strategies for helping department performance.

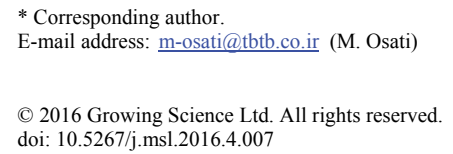




\section{The proposed study}

\subsection{The grey set and grey numbers}

Consider a grey set where two grey numbers $\bar{\mu}_{G}(x)$ and $\underline{\mu}_{G}(x)$ are defined as follows,

$$
\left\{\begin{array}{l}
\bar{\mu}_{G}(x): x \rightarrow[0,1] \\
\underline{\mu}_{G}(x): x \rightarrow[0,1]
\end{array}\right.
$$

where $X=R, x \in X, \underline{\mu}_{G}(x) \leq \bar{\mu}_{G}(x)$, and $\bar{\mu}_{G}(x)$ and $\underline{\mu}_{G}(x)$ are upper and lower bounds of grey membership of $G$. When $\underline{\mu}_{G}(x)=\bar{\mu}_{G}(x)$, grey set $(\mathrm{G})$ is converted to fuzzy set (Julong, 1989; Liu, \& Forrest, 2010). In this paper, we use $\otimes$ to represent grey numbers and the following operations hold,

$$
\begin{aligned}
& \otimes G_{1}+\otimes G_{2}=\left[\underline{G}_{1}+\underline{G}_{2}, \bar{G}_{1}+\bar{G}_{2}\right] \\
& \otimes G_{1}-\otimes G_{2}=\left[\underline{G}_{1}-\bar{G}_{2}, \bar{G}_{1}-\underline{G}_{2}\right] \\
& \otimes G_{1} \times \otimes G_{2}=\left[\operatorname{Min}\left(\underline{G_{1}} \underline{G}_{2}, \underline{G}_{1} \bar{G}_{2}, \bar{G}_{1} \underline{G}_{2}, \bar{G}_{1} \bar{G}_{2}\right), \operatorname{Max}\left(\underline{G}_{1} \underline{G}_{2}, \underline{G}_{1} \bar{G}_{2}, \bar{G}_{1} \underline{G}_{2}, \bar{G}_{1} \bar{G}_{2}\right)\right] \\
& \otimes G_{1} \div \otimes G_{2}=\left[\underline{G_{1}}, \bar{G}_{1}\right] \times\left[\frac{1}{G_{2}}, \frac{1}{\bar{G}_{2}}\right] \\
& -\otimes G_{1}=\left[-\overline{G_{1}},-G_{1}\right] \\
& \otimes G_{1}^{-1}=\left[\frac{1}{\bar{G}_{1}}, \frac{1}{G_{1}}\right] \quad \underline{G}_{1} \neq 0, \bar{G}_{1} \neq 0, \underline{G}_{1} \bar{G}_{1}>0
\end{aligned}
$$

For more details on grey computations, one may look at Liu and Forrest (2010).

\subsection{Balanced score card}

Balance scorecard (BSC) method is a method used in several governmental and non-governmental organizations, substantially. BSC is basically a management system, which help organizations determine their strategies and apply them within the organization (Olson \& Slater, 2002). Kaplan and Norton (1996) are the first who introduced BSC concept in 1992 and implemented it as a performance evaluation system, especially for 12 firms in USA. The aim of BSC is to make necessary changes on traditional performance evaluation model to find more comprehensive and effective evaluation of organizational performance. Note that financial aspect is the only part of organizational performance evaluation in BSC and other characteristics are also considered such as customer, internal business processes and employee's growth and learning, so that performance evaluation model can reach more balance compared with past. These characteristics are essential for perception and implementation of a perfect performance evaluation system and forming of a general set of organization performance indexes for strategic survey on all objectives of a firm. The concept and meaning of the four characteristics are as follow,

1. Financial aspect: this item tests how firms benefit from their strategic activities.

2. Customer aspect: this perspective is associated with the issue that firms should benefit of their inherent and available resources for the distinction among their competitors.

3. Internal business process characteristics: all the strategic activities in any firm executed to satisfy stockholder and customer's needs are considered in this item. General process is begun by perception of customer's requirements and the operational and sale processes are executed after that.

4. Growth and learning characteristics: if firms intend to keep permanent activity and development, they have to concentrate on constant growth and innovation. 
Kaplan and Norton (2000) stated that firms had to emphasize on some rules and regulations such as promoting employees' capabilities and their capabilities, information system performance, persuasion, etc. Performance indexes ought to be adopted properly based on organizational objectives. Index selection plays essential role for learning the required industry performance, since one may wish to consider efficiency of manufacturing operations and build significant advantages by precise investigation of these indexes (Wang et al., 2011). Relationships among various aspects of BSC are shown in Fig. 1.

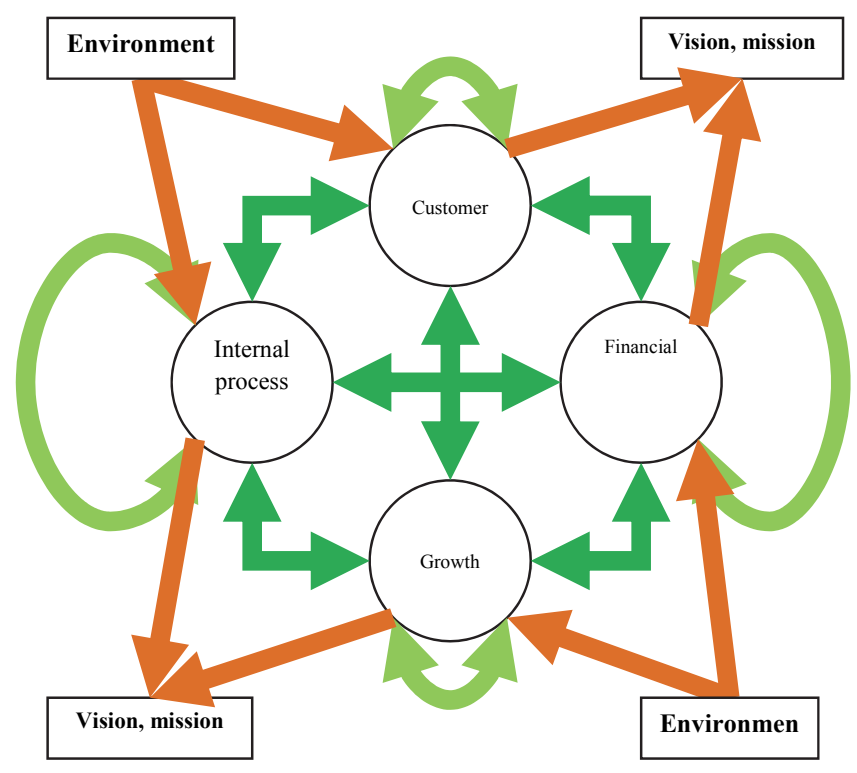

Fig.1. Relations among different aspects of BSC

Kaplan and Norton believed that BSC incorporates influencing and influenced relationships among different indexes in selected aspects.

\subsection{PROMETHEE}

Preference Ranking Organization Method for Enrichment Evaluation (PROMETHEE) (Brans \& Vincke, 1985) is a well-known decision support system dealing with the selection of a set of options on the basis of several criteria with the objective of reaching a ranking among them. PROMETHEE deals with qualitative and quantitative criteria and it can deal with gray numbers.

Step 1: PROMETHEE method begins with the decision matrix as follows

$$
\left[\begin{array}{cccc}
f_{1}\left(a_{1}\right) & f_{2}\left(a_{1}\right) & \ldots & f_{n}\left(a_{1}\right) \\
f_{1}\left(a_{2}\right) & f_{2}\left(a_{2}\right) & \ldots & f_{n}\left(a_{2}\right) \\
\ldots & \ldots & f_{j}\left(a_{i}\right) & \ldots \\
f_{1}\left(a_{m}\right) & f_{2}\left(a_{m}\right) & \ldots & f_{n}\left(a_{m}\right)
\end{array}\right]
$$

where $f_{j}\left(a_{i}\right)$ is the performance of the $\mathrm{i}^{\text {th }}$ alternative in terms of the $\mathrm{j}^{\text {th }}$ criteria. Here $n$ and $m$ are the number of the criteria and the alternatives, respectively. First, a specific preference function has to be defined $\left(\mathrm{P}_{\mathrm{j}}(\mathrm{a}, \mathrm{b})\right)$, which translates the deviation between the evaluations of two alternatives ( $\mathrm{a}$ and $\mathrm{b}$ ) on a specific criterion $f_{j}$ into a preference degree ranging from 0 to 1 . This preference index is an increasing function of the deviation (d) between the scores of the alternatives on the criterion $f_{j}(a)-$ $\left.f_{j}(b)\right)$. In order to choose a specific preference function, six possible shapes of preference functions 
are introduced to the decision-maker by Brans (1986). They are usual shape, U-shape function, V-shape function, level function, linear function and Gaussian function.

$$
P_{j}(a, b)=G_{j}\left(f_{j}(a)-f_{j}(b)\right)
$$

Step 2: In this method the preference is according to the pair-wise comparison of alternatives for each criterion. For this comparison purpose deviation of evaluations of two alternatives are implemented where the higher the deviation the higher the preference. This step includes calculation of preference function $P_{j}(\mathrm{a}, \mathrm{b})$. There are mainly six kinds of generalized preference functions as presented by Brans and Mareschal (2005). However, these preference functions need the definition of some preferential parameters, such as the preference and indifference thresholds criteria.

$P_{j}(a, b)=\left\{\begin{array}{cc}0 & \text { if } \mathrm{f}_{\mathrm{j}}(a)<f_{j}(b) \\ \left(f_{j}(a), f_{j}(b)\right) & \text { otherwise }\end{array}\right.$

For concrete case we specify $p($.$) function as:$

$p\left(\left(f_{j}(a), f_{j}(b)\right)=\left(f_{j}(a)-f_{j}(b)\right.\right.$

In order to define the areas of indifference in the neighborhood of $f(b)$ :

$x=f(a)-f(b)$

\section{Type 1: Usual criteria:}

$P(x)=\left\{\begin{array}{cc}0 & \forall x \leq 0 \\ 1 & \text { otherwise }\end{array}\right.$

\section{Type 2: Quasi criteria:}

$P(x)=\left\{\begin{array}{cc}0 & \forall x \leq l \\ l & \text { otherwise }\end{array}\right.$

Type 3: Criteria with linear preference:

$P(x)=\left\{\begin{array}{cc}x / m & \forall x \leq m \\ 1 & \forall x>l\end{array}\right.$

Type 4: Level criteria:

$P(x)=\left\{\begin{array}{cc}0 & x \leq q \\ 0.5 & q<x \leq q+p \\ 1 & x>q+p\end{array}\right.$

Type 5: Criteria with linear preference and indifference area:

$P(x)=\left\{\begin{array}{cc}0 & x \leq s \\ (x-s) / r & s<x \leq s+r \\ 1 & s+r \leq q+p\end{array}\right.$

Type 6: Gaussian Criteria

$P(x)=\left\{\begin{array}{cc}0 & \forall x \leq 0 \\ 1-e^{-x^{2} / 2 \sigma^{2}} & \forall x>0\end{array}\right.$ 
The value of $\sigma$ is determined by the decision maker.

Step 3: Measure the overall preference index by considering the weight of the individual criteria. It is calculated as follows:

$$
\pi(a, b)=\sum_{j=1}^{j=n} w_{j} P_{j}(a, b)
$$

Here $\pi(a, b)$ is associated with the degree with which alternative $a$ is preferred to $b^{\prime}$ and $\pi(a, b)$ the measure of the degree with which alternative $b$ is preferred to the alternative $i$.

Step 4: Determine the leaving and entering outflow matrix. Leaving or positive ranking outflow for the $i^{\text {th }}$ alternative

$$
\varphi^{+}(i)=\frac{1}{n-1} \sum_{b} \pi(a, b)
$$

Entering or negative ranking outflow for the $i^{\text {th }}$ alternative

$$
\varphi^{-}(i)=\frac{1}{n-1} \sum_{b} \pi(b, a)
$$

where $\mathrm{m}$ is the number of alternatives.

\subsection{The PROMETHEE II complete ranking}

Here, each alternative encounters $(n-1)$ number of other alternatives. The leaving flow expresses how much an alternative dominates the other ones, while the entering flow indicates how much an alternative is dominated by the other ones. Based on these outranking flows, the PROMETHEE I technique gives a partial preorder of the alternatives, whereas, the PROMETHEE II method provides the complete preorder by applying a net flow, though it loses much information of preference relations.

Step 5: Determine the net outranking flow for each alternative as follows:

$$
\varphi(a)=\varphi^{+}(a)-\varphi^{-}(a)
$$

A higher value of $\varphi(a)$ indicates better alternative. Therefore, the best alternative represents the highest $\varphi(a)$ value. From the positive and negative outranking flows, the net outranking flow value is as follows:

$$
\begin{aligned}
& \varphi(a)=\varphi^{+}(a)-\varphi^{-}(a) \\
& \varphi(a)=\frac{1}{m-1} \sum_{j=1}^{n}\left(\sum_{b}\left[P_{j}(a, b)-P_{j}(b, a)\right]\right)
\end{aligned}
$$

Thus, $\varphi(a)=\sum_{j=1}^{n} w_{j} \varphi_{j}(a)$

where, $\varphi_{j}(a)=\sum_{b}\left[P_{j}(a, b)-P_{j}(b, a)\right]$

where $\varphi_{j}(a)$ is the single criterion net flow obtained for $j^{\text {th }}$ criterion.

\section{Case study}

Tehran is one of the mega cities of the world and consumes significant amount of electricity per day. The city is important because it is the host of all governmental agencies and all political and economic decisions are made in this city. Therefore, it is important to use reliable suppliers in accomplishing electricity distribution activities. Presently, electricity contractors are involved in three areas of operations and services, customers and development. The proposed study of this paper plans to rank six contractors $\left(\mathrm{T}_{1}, \ldots, \mathrm{T}_{6}\right)$ in terms BSC four perspectives, Financial $\left(\mathrm{C}_{1}\right)$. Customers $\left(\mathrm{C}_{2}\right)$, Internal processes $\left(\mathrm{C}_{3}\right)$, and learning and growth $\left(\mathrm{C}_{4}\right)$. There were five experts who could help us complete the survey and we have decided to participate all of them in our study. The study uses PROMETHEE technique to rank the contractors using grey numbers, which are given in Likert scale as follows, 


\begin{tabular}{cccccc}
\hline Verbal language & Very low & Low & Medium & High & Very high \\
\hline Abbreviation & VL & L & M & H & VH \\
$\otimes G$ & {$[0,1]$} & {$[1,4]$} & {$[4,6]$} & {$[6,9]$} & {$[9,10]$} \\
\hline
\end{tabular}

The experts' votes are integrated as follows,

$$
\otimes G_{i j}=\frac{1}{K}\left[\otimes G_{i j}^{1}+\otimes G_{i j}^{2}+\cdots+\otimes G_{i j}^{k}\right]
$$

where $\otimes G_{i j}^{k}(i=1,2, \ldots, m ; g=1,2, \ldots, n)$ is associated with kth expert for ith alternative in terms of jth criterion, which can be stated as a grey number $\otimes G_{i j}^{k}=\left[G_{i j}^{k}, \bar{G}_{i j}^{k}\right]$. Table 1 shows the results of our survey,

Table 1

The results of the grey numbers

\begin{tabular}{|c|c|c|c|c|c|c|c|}
\hline$T_{i}$ & $C_{j}$ & $D_{1}$ & $D_{2}$ & $D_{3}$ & $D_{4}$ & $D_{5}$ & $\otimes G_{i j}$ \\
\hline \multirow{4}{*}{$\mathrm{T}_{1}$} & $\mathrm{C}_{1}$ & $\mathrm{VH}$ & $\mathrm{H}$ & $\mathrm{H}$ & $\mathrm{H}$ & $\mathrm{VH}$ & {$[7.2,9.4]$} \\
\hline & $\mathrm{C}_{2}$ & $\mathrm{H}$ & VH & VH & VH & $\mathrm{H}$ & {$[7.8,9.6]$} \\
\hline & $\mathrm{C}_{3}$ & M & M & VH & M & VH & {$[6,7.6]$} \\
\hline & $\mathrm{C}_{4}$ & M & M & $\mathrm{VH}$ & $\mathrm{VH}$ & $\mathrm{H}$ & {$[6.4,8.2]$} \\
\hline \multirow{4}{*}{$\mathrm{T}_{2}$} & $\mathrm{C}_{1}$ & $\mathrm{VH}$ & VH & $\mathrm{VH}$ & $\mathrm{VH}$ & $\mathrm{VH}$ & {$[9,10]$} \\
\hline & $\mathrm{C}_{2}$ & M & $\mathrm{H}$ & M & M & M & {$[3.6,6.6]$} \\
\hline & $\mathrm{C}_{3}$ & M & $\mathrm{H}$ & M & M & $\mathrm{H}$ & {$[4.8,7.2]$} \\
\hline & $\mathrm{C}_{4}$ & $\mathrm{H}$ & $\mathrm{H}$ & M & M & $\mathrm{M}$ & {$[4.8,7.2]$} \\
\hline \multirow{4}{*}{$\mathrm{T}_{3}$} & $\mathrm{C}_{1}$ & $\mathrm{H}$ & $\mathrm{H}$ & $\mathrm{H}$ & $\overline{\mathrm{H}}$ & $\mathrm{H}$ & {$[6,9]$} \\
\hline & $\mathrm{C}_{2}$ & M & M & L & L & M & {$[2.8,5.2]$} \\
\hline & $\mathrm{C}_{3}$ & $\mathrm{H}$ & M & $\mathrm{L}$ & L & L & {$[2.6,5.4]$} \\
\hline & $\mathrm{C}_{4}$ & L & $\mathrm{L}$ & L & L & $\mathrm{L}$ & {$[1,4]$} \\
\hline \multirow{4}{*}{$\mathrm{T}_{4}$} & $\mathrm{C}_{1}$ & $\mathrm{M}$ & $\mathrm{M}$ & M & M & M & {$[4,6]$} \\
\hline & $\mathrm{C}_{2}$ & L & $\mathrm{L}$ & VL & VL & VL & {$[0.4,2.2]$} \\
\hline & $\mathrm{C}_{3}$ & $\mathrm{~L}$ & VL & VL & $\mathrm{L}$ & $\mathrm{L}$ & {$[0.4,2.2]$} \\
\hline & $\mathrm{C}_{4}$ & M & $\mathrm{L}$ & M & M & M & {$[3.4,5.6]$} \\
\hline \multirow{4}{*}{$\mathrm{T}_{5}$} & $\mathrm{C}_{1}$ & M & M & M & M & M & {$[4,6]$} \\
\hline & $\mathrm{C}_{2}$ & M & L & L & $\mathrm{L}$ & $\mathrm{L}$ & {$[1.6,4.4]$} \\
\hline & $\mathrm{C}_{3}$ & M & M & M & M & M & {$[4,6]$} \\
\hline & $\mathrm{C}_{4}$ & $\mathrm{VL}$ & $\mathrm{L}$ & $\mathrm{L}$ & $\mathrm{L}$ & $\mathrm{L}$ & {$[0.8,2.6]$} \\
\hline \multirow{4}{*}{$\mathrm{T}_{6}$} & $\mathrm{C}_{1}$ & $\mathrm{~L}$ & $\mathrm{~L}$ & $\mathrm{~L}$ & $\mathrm{~L}$ & $\mathrm{~L}$ & {$[1,4]$} \\
\hline & $\mathrm{C}_{2}$ & M & M & M & M & M & {$[4,6]$} \\
\hline & $\mathrm{C}_{3}$ & L & M & M & $\mathrm{L}$ & L & {$[2.2,4.8]$} \\
\hline & $\mathrm{C}_{4}$ & M & M & $\mathrm{H}$ & $\mathrm{H}$ & $\mathrm{H}$ & {$[5.2,7.8]$} \\
\hline
\end{tabular}

Now grey relational matrix is formed based on Eq. (14) and the results are summarized in Table 2.

$$
D=\left[\begin{array}{ccc}
\bigotimes G_{11} & \cdots & \bigotimes G_{1 n} \\
\vdots & \ddots & \vdots \\
\bigotimes G_{m 1} & \cdots & \bigotimes G_{m n}
\end{array}\right]
$$

\section{Table 2}

The summary of grey relational matrix

\begin{tabular}{ccccc}
\hline & $C_{1}$ & $C_{2}$ & $C_{3}$ & $C_{4}$ \\
\hline$A_{1}$ & {$[7.2,9.4]$} & {$[7.8,9.6]$} & {$[6,7.6]$} & {$[6.4,8.2]$} \\
$A_{2}$ & {$[9,10]$} & {$[3.6,6.6]$} & {$[4.8,7.2]$} & {$[4.8,7.2]$} \\
$A_{3}$ & {$[6,9]$} & {$[2.8,5.2]$} & {$[2.6,5.4]$} & {$[1,4]$} \\
$A_{4}$ & {$[4,6]$} & {$[0.4,2.2]$} & {$[0.4,2.2]$} & {$[3.4,5.6]$} \\
$A_{5}$ & {$[4,6]$} & {$[1.6,4.4]$} & {$[4,6]$} & {$[0.8,2.6]$} \\
$A_{6}$ & {$[1,4]$} & {$[4,6]$} & {$[2.2,4.8]$} & {$[5.2,7.8]$} \\
\hline
\end{tabular}


Next, we use Gaussian Preference function to compute the weights of alternatives and criteria and Table 3 summarizes the results.

\section{Table 3}

The results of the implementation of Gaussian Preference function

\begin{tabular}{ccccc}
\hline & $C_{1}$ & $C_{2}$ & $C_{3}$ & $C_{4}$ \\
\hline Value & Min & Max & Max & Max \\
S & -10 & 5 & 5 & 5 \\
Weight of alternatives & {$[0.72,0.94]$} & {$[0.48,0.72]$} & {$[0.48,0.72]$} & {$[0.34,0.56]$} \\
\hline$T_{1}$ & {$[7.2,9.4]$} & {$[7.8,9.6]$} & {$[6,7.6]$} & {$[6.4,8.2]$} \\
$T_{2}$ & {$[9,10]$} & {$[3.6,6.6]$} & {$[4.8,7.2]$} & {$[4.8,7.2]$} \\
$T_{3}$ & {$[6,9]$} & {$[2.8,5.2]$} & {$[2.6,5.4]$} & {$[1,4]$} \\
$T_{4}$ & {$[4,6]$} & {$[0.4,2.2]$} & {$[0.4,2.2]$} & {$[3.4,5.6]$} \\
$T_{5}$ & {$[4,6]$} & {$[1.6,4.4]$} & {$[2.2,4.8]$} & {$[0.8,2.6]$} \\
$T_{6}$ & {$[1,4]$} & {$[4,6]$} & {$[5.2,7.8]$} \\
\hline
\end{tabular}

Next, we convert the grey numbers to crisp numbers and Table 4 shows the results.

\section{Table 4}

The summary of the conversion of grey numbers to crisp numbers

\begin{tabular}{ccccc}
\hline & $C_{1}$ & $C_{2}$ & $C_{3}$ & $C_{4}$ \\
\hline Value & Min & Max & Max & Max \\
S & -10 & 5 & 5 & 5 \\
Weight of alternatives & 0.83 & 0.6 & 0.6 & 0.45 \\
\hline$T_{1}$ & 8.3 & 8.7 & 6.8 & 7.3 \\
$T_{2}$ & 9.5 & 5.1 & 4 & 6 \\
$T_{3}$ & 7.5 & 4 & 1.3 & 2.5 \\
$T_{4}$ & 5 & 1.3 & 5 & 4.5 \\
$T_{5}$ & 5 & 3 & 3.5 & 1.7 \\
$T_{6}$ & 2.5 & 5 & & 6.5 \\
\hline
\end{tabular}

Using Gaussian preference function we may find the weights of alternatives and criteria and Table 5 summarizes the results.

\section{Table 5}

The results of the implementation of Gaussian preference function

\begin{tabular}{ccccccc}
\hline & $T_{1}$ & $T_{2}$ & $T_{3}$ & $T_{4}$ & $T_{5}$ & $T_{6}$ \\
\hline$T_{1}$ & 0 & 0.067 & 0.189 & 0.182 & 0.216 & 0.108 \\
$T_{2}$ & 0 & 0 & 0.0637 & 0.155 & 0.081 & 0.028 \\
$T_{3}$ & 0.0011 & 0.0066 & 0 & 0.0657 & 0.0071 & 0.0012 \\
$T_{4}$ & 0.0177 & 0.0318 & 0.024 & 0 & 0.0263 & 0 \\
$T_{5}$ & 0.0176 & 0.0318 & 0.0149 & 0.0715 & 0 & 0.01 \\
$T_{6}$ & 0.0518 & 0.0735 & 0.0927 & 0.121 & 0.35 & 0 \\
\hline
\end{tabular}

The input and the output flows are calculated as follows,

$$
\begin{aligned}
& \emptyset^{+}\left(T_{i}\right)=\sum_{\mathrm{k}=1}^{\mathrm{m}} \pi\left(T_{i}, T_{k}\right), \\
& \emptyset^{-}\left(T_{i}\right)=\sum_{\mathrm{k}=1}^{\mathrm{m}} \pi\left(T_{k}, T_{i}\right), \\
& \varnothing\left(T_{i}\right)=\emptyset^{+}\left(T_{i}\right)-\emptyset^{-}\left(T_{i}\right), \forall i \in\{1, \ldots, m\} .
\end{aligned}
$$

and the results are summarized in Table 6 as follows, 
Table 6

The results of input/output flow

\begin{tabular}{ccccc}
\hline & $\emptyset^{+}$ & $\emptyset^{-}$ & $\emptyset$ & Rank \\
\hline$T_{1}$ & 0.762 & 0.088 & 0.674 & 6 \\
$T_{2}$ & 0.328 & 0.21 & 0.118 & 4 \\
$T_{3}$ & 0.082 & 0.384 & -0.302 & 3 \\
$T_{4}$ & 0.099 & 0.595 & -0.496 & 2 \\
$T_{5}$ & $\mathbf{0 . 1 4 6}$ & $\mathbf{0 . 6 8}$ & $\mathbf{- 0 . 5 3 4}$ & $\mathbf{1}$ \\
$T_{6}$ & 0.689 & 0.147 & 0.542 & 5 \\
\hline
\end{tabular}

\section{Conclusion}

Performance measurement in energy industry plays essential role on improving the economy. Electricity is also among the most important components of energy in mega cities like Tehran. The lack of a good service in this city may result unpleasant consequences on most civilians who live in this city. In this paper, we have presented an empirical investigation to measure the performance of six major electricity contractors in city of Tehran, Iran. The implementation of the proposed study has implemented grey numbers to handle any uncertainty associated with numbers. The study has also adopted four main perspectives used in BSC method as part of PROMETHEE method to rank different contractors.

\section{Acknowledgement}

The authors would like to thank the anonymous referees for constructive comments on earlier version of this paper.

\section{References}

Bentes, A. V., Carneiro, J., da Silva, J. F., \& Kimura, H. (2012). Multidimensional assessment of organizational performance: Integrating BSC and AHP. Journal of Business Research, 65(12), 1790-1799.

Brans, J. P., \& Vincke, P. (1985). Note-A preference ranking organization method: (The PROMETHEE method for multiple criteria decision-making). Management science, 31(6), 647-656.

Brans, J. P., \& Mareschal, B. (2005). PROMETHEE methods In Multiple criteria decision analysis: state of the art surveys (pp. 163-186). Springer New York

Julong, D. (1989). Introduction to grey system theory. The Journal of grey system, 1(1), 1-24.

Kaplan, R. S. \& Norton, D. P. (1996). Using the balanced scorecard as a strategic management system. Harvard Business Review (Jan-Feb), 74 (1), 75-85.

Kaplan, R. S. \& Norton, D. P. (2000). The strategy-focused organization. USA: Harvard Business School Press.

Lee, A. H., Chen, W. C., \& Chang, C. J. (2008). A fuzzy AHP and BSC approach for evaluating performance of IT department in the manufacturing industry in Taiwan. Expert systems with applications, 34(1), 96-107.

Liu, S., \& Forrest, J. Y. L. (2010). Grey systems: theory and applications. Springer.

Olson, E.M., \& Slater, S.F. (2002). The balanced scorecard, competitive strategy, and performance. Business Horizons, 45, 11-16.

Tseng, M. L. (2010). Implementation and performance evaluation using the fuzzy network balanced scorecard. Computers \& Education, 55(1), 188-201.

Wang, C.H., Lu, I.Y., \& Chen, C.B. (2010). Integrating hierarchical balanced scorecard with non-additive fuzzy integral for evaluating high technology firm performance. International Journal of Production Economics, $128,413-426$.

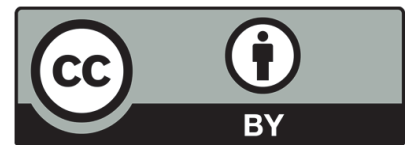

(C) 2016 by the authors; licensee Growing Science, Canada. This is an open access article distributed under the terms and conditions of the Creative Commons Attribution (CC-BY) license (http://creativecommons.org/licenses/by/4.0/). 